\title{
SOCIO-ECONOMIC ASPECTS OF DEVELOPMENT OF SMALL INNOVATIVE BUSINESS IN RUSSIA
}

\author{
Yuri Anatolievich Doroshenko* \\ Belgorod State Technological University named after V.G. Shukhov, Russia \\ Liudmila Alekseevna Minaeva \\ Belgorod State Technological University named after V.G. Shukhov, Russia \\ Žana Nikolajevna Avilova \\ Belgorod State Technological University named after V.G. Shukhov, Russia \\ Irina Vladimirovna Somina \\ Belgorod State Technological University named after V.G. Shukhov, Russia \\ Olga Viktorovna Leonova \\ Belgorod State Technological University named after V.G. Shukhov, Russia
}

This article describes the main components of creating an innovative product, foundinterdependence of costs for research \& development and patent activity in the country. It shows the comparative characteristics of small innovative business's systems in the industrially advanced countriesand Russia. The positive role of copying foreign production of innovative goods and the use of technology was identify. The basic socio-economic problems affecting the active development of innovative entrepreneurship were distinguished. Considered the Russian experience in the development of small and medium-sized enterprises in pre-revolutionary and Soviet times (artisanal-cooperative movement). Recommendations for the creation of innovation climate, based on the support of the invention and the mentality of the Russians were given in this article.

Key words: Small innovation business, Socio-economic problems, Innovative climate, Research and development, Patent activity, Invention

\section{INTRODUCTION}

In recent years owing to the promotion of innovation in Russian society, it is particular relevance to research and development of innovative component in the small and medium business. The importance of the problem is reinforced by the fact that small and medium-sized innovative enterprises are able to be the driver in matters of import, support for self-sufficiency of the country under Western sanctions. At the present time in Russia there is no effective model for integrating of small innovative enterprises and institutions which are supported them in a single system, there are only a set of disparate infrastructure enterprises and organizations, which have not common policy and strategy. Attempts to copyexperience of the world innovative powers inthe developing of small innovative enterprises in the industry did notbringgoodresults.

\section{METHODOLOGY}

Researchers problems of development and support of small and medium-sized businesses allo- cate a number of socio-economic issues hindering the strategic development of small business: increasing the burden on businesses, increase tax rates, control and supervision and administrative barriers, etc. There are also some socio-culturalbarriers: a complex of traditions and stereotypes, predetermines the neglect of the "ordinary innovation" that improve people's daily lives, and distrust of inventors and marketers, and cultural backwardness of the collective intellectual work, etc. Such problems of small and medium-sized innovative companies considered by the Russian economists and sociologists: I.G.Andreeva, N.V.Astafieva, D.I.Valigurskiy, V.D.Denisov, Y.A.Doroshenko, N.V.Kazakova, D.A.Kazmenkov, V.M.Kutuzov, A.M.Orekhov, I.N.Savelieva, M.Y.Shestopalov, etc. [01, 02, 03, etc.] At present, Russia has created the basic elements of the main innovation support, including for small innovative enterprises. The state program of the Russian Federation were developed: "Economic development and innovative economy" (from July 20, 2013 N 1260-p); "The develop- 
ment of science and technology" for 2013-2020 (December 20, 2012 № 2433-p), etc. Presidential Decree of May 7, 2012 N 596 "On the long-term government economic policy," etc. The Government of the Russian Federation tasked increasing the share of high-tech and knowledge-intensive production industries in the GDP by 2018 in 1.3 times regarding the level in 2011. However, the ratio in some regions to small business demonstrates that it is still just a source of filling the regional budget, and not as an institution fulfills an important social function. Traditional, sometimes, inefficient forms and methods of workingof the executive authority of the regionsmostly dominated and there is no comprehensive and systematic approach.

\section{MAIN PART}

Innovative activity is usually time-consuming and for transferring the results of research and development work ( $R \& D$ ) in the production is necessary a sufficient number of investments in fixed capital but this is one of the main problems for small and medium-sized businesses. There is no any country in the world which is entirely self-sufficient in technology. However, for any developed country it is always important to have its own scientific and technical resource and Russia is taking certain steps for development and usingof this resource [04, p.89]. Special attention is paid by the state government to small innovative enterprises. The mechanism of support of innovative activity of small enterprises was developed. It is include: direct government incentives for research and development activities; indirect government incentives science; provision of various kinds of benefits for subjects of the innovation process; the formation of innovative climate in the economy [05].

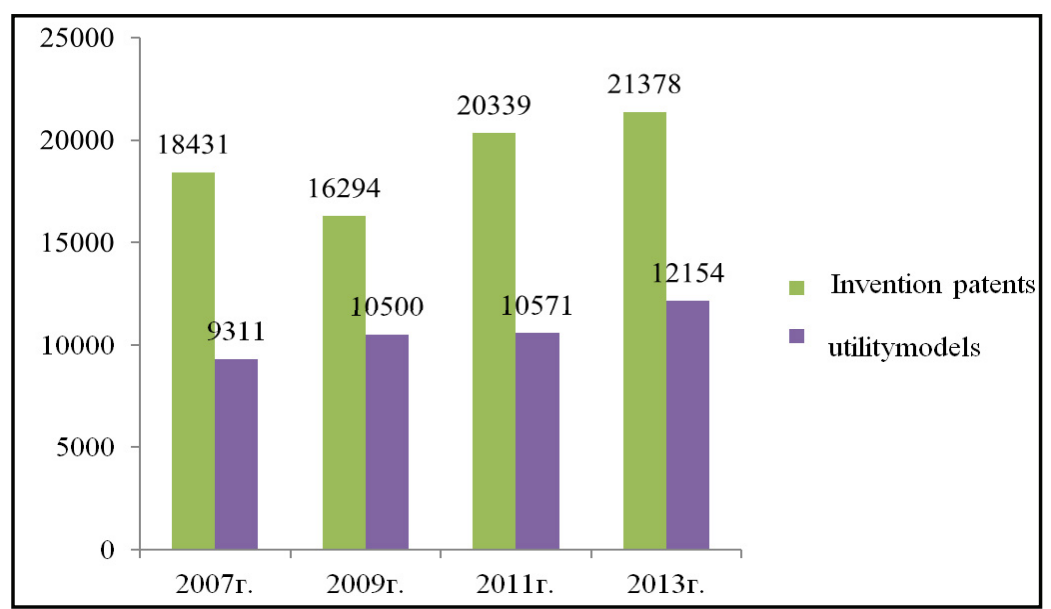

Figure 1: Inflowing of patent applications in Russia in the 2007-2013
Usually creation of an innovative product takes place in three stages:

- scientific and research work,

- experimentaldesigndevelopment,

- production of the products.

Moreover, all these steps should have an equal attraction for media creativity. However, in Russia, a stable company tries to select the last stage - production of products, realizing more often, foreign ideas. This fact is not a distinctive feature of Russia, many developed countries use this way. To search ideas and research work takes for $53 \%$ of the costs of the innovation process, whereas the development and manufacturing requires $26 \%$ of the total investment. In addition, salary of experts in science \& research work is $30 \%$ lower than nationwide, such activities are not popular in Russia. In 2009-2013 we noticed increase in patent activity, but it is insignificant (Figure 1)[06]. The number of inventionpatents increased by $5.1 \%$, patents for utility models increased by $15 \%$. Compared with countries whose economies are based on innovative development this growth is not enough. In China, in 2013 it was registered 830000 patent applications filed by inventors. Comparedto 2012 increasewas $27 \%$, approved 144,000 patents. For the research \& develop in China in 2012 was sent to 160 billionUSD, scientific work takes 2.9 millionpeople [07]. In Russia, in the same period, the cost of research\& develop work were slightly less than 700 billion rub.,i.e. about 18 billion USD. The number of research organizations from year to year decreasing: in 2013 there were 1,719, while in 2000 - 2686. Design offices, design \& survey organizations cover $10 \%$ of all Russian companies that perform research and development.Insufficiently active development of small innovative enterprises in Russia is due to several socio-economic factors. Comparative characteristics of small innovative business systems in the industrialized countries and Russia is presented in the table.

Often innovation activities is identified as scientific activities. But the difference lies in the fact that scientific activities as an intellectual activity, focused on the preparation and use of new knowledge for different sectors and activities. While innovation activities basically includes the commercialization of existing knowledge, 
technology, equipment [08, p. 19]. Scientific research, new technical solutions, optimization of processes to produce higher and higher scientific and technical results - a scientific activity which does not always lead to the initiation of the process of commercialization, i.e. inclusion of new knowledge in commercial circulation [09]. For the successful implementation of innovations requires feedback from the market. The market will demand only the innovative products that satisfy the needs of potential buyers. Competition in the market of innovative products and technologies usually begins at the stage of generating ideas. For example, in Denmark, the Danish Product Company performed an experiment to find new ideas and new partners. From 5000 reviewed scientific results only 350 (7\%) were truly original and had no evidence of copyright infringement, $93 \%$ of the remaining technologies were more or less borrowed from each other. Similar studies were carried out in other countries, and everywhere, and the ratio considered successful proposals were about the same. The fact that most of the inventions is not converted into innovative products, is the fact. Many countries covered deficit of its own innovative products by the copying of inventions, producing a replica of products (from the English - Replica - a reproduction, an exact copy). So in China, despite the high percentage of innovative technologies (made $80 \%$ of new products), one of the main challenges to innovation lies in the fact that, up to the Chinese manage much better than creating original ideas and technologies [10].

Table 1: Comparative characteristics of systems of small innovative enterprises (SIE) in the industrialized countries and Russia

\begin{tabular}{|c|c|c|}
\hline & Industrialized countries & Russian Federation \\
\hline 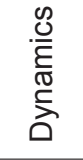 & $\begin{array}{l}\text { The formation of a long historical period, based } \\
\text { on the political will, the systemic nature of inno- } \\
\text { vation in small business in the industry }\end{array}$ & $\begin{array}{l}\text { Small innovative enterprises system in the industry, there } \\
\text { nominally indirect confirmation of that is the support of iner- } \\
\text { tia, based on energy resources development }\end{array}$ \\
\hline$\frac{\text { 응 }}{\frac{.0}{0}}$ & $\begin{array}{l}\text { A clear innovation policy and initial focus on the } \\
\text { development of entrepreneurial activity, thereby } \\
\text { creating a favorable innovation climate }\end{array}$ & $\begin{array}{c}\text { There is no consistent government policies to support the } \\
\text { development of entrepreneurship and innovation climate (as } \\
\text { evidenced by the faster growth of tariffs for gas and electric- } \\
\text { ity, tax barriers, etc.) }\end{array}$ \\
\hline 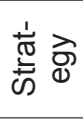 & $\begin{array}{c}\text { Relying on the resources of small innovative } \\
\text { enterprises in the strategy for socio-economic } \\
\text { development }\end{array}$ & $\begin{array}{l}\text { Frequent change of policy preference for large and small } \\
\text { businesses; lack of emphasis on the development of the SIE } \\
\text { in the industry due to the underestimation of its potential }\end{array}$ \\
\hline $\begin{array}{l}\frac{\infty}{0} \\
\circ\end{array}$ & $\begin{array}{l}\text { The variety of models of innovation (basic } \\
\text { models - Anglo-Saxon, European, Scandinavian, } \\
\text { Asian) with different set of measures to sup- } \\
\text { portofsmall innovative enterprises }\end{array}$ & $\begin{array}{l}\text { Attempts to find a "universal" model without considering the } \\
\text { peculiarities of Russian business culture; chaotic and incon- } \\
\text { sistent decision-making and incentive measures; inadequate } \\
\text { legislation and lack of effective mechanisms for implementa- } \\
\text { tion of laws }\end{array}$ \\
\hline 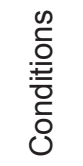 & $\begin{array}{l}\text { Emphasis on the development of institutions to } \\
\text { support innovation in small business and entre- } \\
\text { preneurial culture }\end{array}$ & $\begin{array}{l}\text { Trying to mechanical transfer of foreign experience without } \\
\text { the formation of institutions for development of entrepreneur- } \\
\text { ship and innovation }\end{array}$ \\
\hline
\end{tabular}

For Russia which is currently at the stage of borrowing standards of consumptionfrom developed countries, the volume of technology developed by itself, is substantially less than the volume of technologies that it must buy for normal development, or at least to ensure responsiveness to world achievements. The solution of the problem - increasing the share of high-tech and knowledge-intensive sectors of the economy in GDP is largely dependent on overcoming a significant part of the difficulties and obstacles to the formation and development of Russian small innovative businesses, which lie outside the scope of most small businesses. Innovative processes in small businesses are in a constantly changing environment, due to the:

- changes in market conditions;

- the influence of socio-political nature;

- the dynamics of the organizational environment in which takes place the process of innovation;

- the specificity of the structure and dynamics of (economic) micro and macro environment.

A particular problem is the distrust of the Russians in the field of industrial business. Citizen of $R F$ in recent years have a lot of reasons to 
lose confidence in: a devastating administrative reforms, the collapse of the banks, the devaluation of the ruble, etc. We should add one more important circumstance. The state is not doing enough to improve the credibility of the small innovative enterprises and products produced on them. First, Russia lacks the legal framework that would allow due consideration to the rights of small innovative businesses, including research and production enterprises. Second, the practice of creating executive federal and regional authorities of the special conditions for certain small and medium-sized enterprises contribute to provide them with additional competitive advantages, which complicates the work of other innovative enterprises. Third, the allocation of public funds to support specific innovative companies does not give tangible results for the economy and society as a whole. Most erudite work of scientific and industrial enterprises are not measured properly. For increasing confidence in the small business innovation and the creation of an innovative society, the Russian government should direct its efforts, which should be based on three factors:

1) The generation of new knowledge in the field of science, technology and management.

2) The presence of a highly self programmable workforce to use the new knowledge to improve productivity (labor of this type is a direct result of the quality and quantity of university graduates).

3) Support for entrepreneurs with the opportunity and want to take the risk in the field of transformation of innovative business projects in real business [11].

Solving the problem of creating innovative products or production of replica products should be based on the mentality of the Russians and the present state of Russian experience. Domestic mentality as subliminal psycho-social program of action and behavior of people, the nation in general, manifested in consciousness and practice. If a feature of the German mentality is punctuality, English - conservatism, American - pragmatism, Japan - paternalism, the Russian - a kind of polarity, the pursuit of the grotesque, bring any situation to the extreme on the one hand, and long-suffering, self-sacrifice, on the other hand. Such qualities of the Russian soul in the past were based on the latest achievements of scientific and technical progress. From Asia, Russia absorbed form of groupthinking- group- thinking, from Europe - its inherent individualism outlook. Group thinking and individualism are at odds with each other due to the polarity of their foundations. Their ratio in the course of historical development has not been constant. Before the revolution the communal tradition was decisive. In Soviet Union times, team spirit, faith in bright ideals was the basis of many achievements. The optimal combination of group thinking and individualism manifested in artisanal movement. Production cooperatives as a form of organization of labor and entrepreneurship in small (by pre-revolutionary terminology artisanal) industry took in the late nineteenth and early twentieth century, an important place in the structure of the Russian economy. Their importance in the economic life by the fact that before the revolution of 1917 in Russia, there were 7.3 million industrial workers. Only 2.7 million (36.4\%) were employed in large industrial enterprises, the remaining 4.6 million $(63.6 \%) 1$ - in small-scale industry, the main form of organization which was co-operative. In the context of rapid industrialization and monopolization of big industry production cooperatives meet the needs of the population in everyday goods and services. Before the revolution, some industries were completely concentrated in the hands of small manufacturers: manufacturing boots - $88 \%$ of the total production, tailoring production - $97 \%$, footwear - 94\%, denoted - 99\%, etc. [12]. To enhance the functioning of the farm workers conducted the following activities:

- In order to increase productivity of work carried out specialization and replacement of manual labor by machine, most machines designed porters themselves;

- In order to reduce material consumption of products was carefullyanalyzed each stage of the production process, allowing the process to identify ways to reduce waste;

- In order to minimize costs it was reorganization of the management structure.

Innovative technological solutions were used in cooperatives of V.Tumanov involved in gold mining in 1957. They were first used hydroelevators driven by diesel engines, which was new in the area, where there is no energy. Development and application of advanced technologies in such cooperatives was aimed at saving fuel, material resources, greater productivity and greater production of gold. When Stalin ruled the country more than 114000 workshops and enterprises of differ- 
ent directions - from the food to the metalworking and jewelry from up to the chemical industry were in the country. About 2 million people worked there, they produced almost $6 \%$ of the gross industrial output of the USSR, the artels and cooperatives produces $40 \%$ of furniture, $70 \%$ metal utensils, just over a third jersey, almost all the children's toys. In the enterprise sector employed about 100 engineering offices, 22 experimental laboratories and even two research institutes. At the same time, the farm was created not only to household items like dishes, clothes, shoes and knitwear. Artels manufactures high-tech products often even before its release has been adjusted to the Soviet state enterprises, i.e.it was actually the vanguard of technological and technical industry [13]. Artels and the community were interconnected subsystems of national public order. The cooperative was expressed searcher beginning, popular entrepreneurship, creative exploration of outer space life of the country, those niches in it that require filling and development. The team of Russian people was to experiment, risk, social work, honing skills, developed entrepreneurshipand curiously studied the social life, nature and the economy of Russia, especially its regions. No wonder the majority of artisanal occupations stuck filled with a deep sense of the concept of "trading" - people in the sharpened their thinking and skills learned the diversity of life, the richness of its features. Talented people through this kind of activity could bring reveal their talents[14]. According to many experts, under Western sanctions and economic crisis artisanal work is quite promising. The revival of artisanal as generally acceptable forms of work organization in small and mediumsized enterprises will help revive the economy. The success of the production of innovative enterprise depends largely on the presence of the inventors and the spirit of invention. The inventors did not "appear" out of nowhere. The propensity for invention, manifested at an early age, must be developed. In Soviet times, the development of children's inventions was given enough attention. Many engineers and scientists to innovate, as children attended mug young technology, various scientific sections. In the USSR, it was 11292 model aircraft sections, only in Moscow it was 1720. Now there are only 23 in the capital of Russia. Russian inventors and innovators took part in such sections. Since July 1944, when Stalin had received information about modern German weapons before the end of the year in the implementation of the missile and space programs inJournal of Applied Engineering Science 13(2015)4,343 volving more than 6,000 engineers and designers. In parallel with this project to develop nuclear project, which was attended by no less technically trained and educated workers. Researchers of the phenomenon - the emergence of a large number of inventors in such a short time, found a direct relationship: they all started in the children's technical creativity. In the 1990s, the Russian model aircraft clubs actively attended by representatives of foreign companies (South Korea, Germany, USA) [15]. Methods of communication, education techniques have been fully accepted by them and adapted to their territories.

\section{CONCLUSION}

Despite for some supportfrom the state governmentto small innovative enterprises, there is no systematic approachin society. All elements of the support mechanism and the development of innovative activity of small enterprises should be linked, complement each other. However, the economic crisis imposed the sanctions by Western countries, the difficult political situation in the mechanism of action has been some controversy due to the difference of strategic and current objectives of the state. On the one hand the objective reality is the need for the speedy reconstruction of the economy on the innovative development, on the other hand - the need to counter the influence of the crisis, the desire with the resources available to prevent the decline in living standards. Russia has a positive experience of the creation of small innovative enterprises and innovation climate. Many research institutes and design bureaus effectively worked in Soviet Union time. These innovations are used in the upstream and downstream sectors of the economy. For large enterprises existed research laboratories and pilot production. University students get the skills of research and practical work in laboratories and factories, often joining in innovation in the period of study. Successfully operated cooperatives and cooperatives. The use of the experience, a comprehensive approach to creating a climate for innovation will allow Russia to come out unscathed from the economic crisis and to achieve strategic goals. Establishment of small innovative enterprises as a kind of industrial cooperatives will contribute to solving urgent social and economic problems:

- Actively introduce Russian innovations in small and medium business and / or produce replica products, thereby solving the problem of import substitution; 
- Increase the number of jobs, raising living standards of Russians, thus swelling the ranks of the middle class;

- - Full use of the experience and the positive features of the Russian mentality, to create conditions for the disclosure of talents and creative abilities of employees.

- "Growing" Inventors, innovators should be carried out in two directions. One of the directions - promotion of engineering excellence, involvement of students in technical creativity of children, and through it - the Russian industry, science and discovery. The second trend - creation and technical support for these groups kind of centers of children's creativity.

\section{Findings}

1. Innovative activity is resource-intensive and costly investment, which is one of the main problems for small and medium-sized businesses. Sustainable small (average), the company aims to use already developed technologies.

2. There is no insufficient growth in patent activity in Russia, the cost of research work is small, the number of research and design organizations reduced. The deficit of its own innovative products to some extent covered by copying foreign technologies.

3. The main problems which are hindering for development of innovative small businesses, particularly in the manufacturing sector: the incompleteness of the legal framework for the functioning of small innovative business; distrust of the results of its activities; insufficient use of existing experience and positive components of Russian mentality.

4. In order to solve social and economic problems of small innovative businesses there should be state and society requires a comprehensive approach, based on - the creation of investment climate in the country.

\section{ACKNOWLEDGEMENTS}

The article was published with the financial support from Ministry of Education and Science of the Russian Federation within the framework of state assignment to the project \#26.1511.2014K "Theory and methodology of managing innovational and investment processes in small business enterprises."

\section{REFERENCES}

1) Uluykaev, A., 2015. Small and medium enterprises can prevent unnecessary risks the stability of the state structure. Ministry of Economic Development.

2) Doroshenko, Y.A., Somina, I.V., Komissarov, S.A., Doroshenko, S.Y., 2015. The Essence and Characteristics of Investment Processes in Small Innovative Enterprises. Asian Social Science, 11 (6): 185-191.

3) Doroshenko, Y.A., Somina, I.V., Komissarov, S.A., 2013. Sources of Financing and Innovative and Investment Activity of Small Enterprises. World Applied Sciences Journal, 25 (6): 975-982.

4) Antonec, V.A., Nechayev, N.V., Homkin, K.A., Shvedova, V.V., 2009. Business Innovation: building models of commercialization of promising developments. pp. 320.

5) Gamidullaev, R.B., Gamidullaeva, L.A., 2014. Investigation of mechanisms of the state support of small innovative business: functional aspect of resource. Modern problems of science and education

6) Claims for patents and issue of security documents in Russia, on the subjects of the Russian Federation. // State Statistics Committee, 24.07.2014

7) China once again the leader in the number of inventions // Business Club SinoClub. 28.02.2014. [electronic resource] http://sinoclub.ru/article-97-1.html

8) Zhelamsky, M.V., 2009. Where that will take? Project Management, 4 (17).

9) Doroshenko, Y.A., Bukhonova, S.M., Minaeva, L.A., Somina, I.V., Manin, A.V., 2014. The assessment of the sectorR\&D potential: on the exampleof the Belgorod region. International Journal of Applied Engineering Research (IJAER), 9 (22): 16871-16880.

10) Small business in China. Socioeconomic portal. 12.02.2015. [electronic resource] http://ru.exrus.eu/Maly-biznes-v-Kitaye-id4e70d3786ccc19126a0006cf

11) M. Castells, 2004. Galacticalnternet. U-Factoria.

12) Belonovskaya, A.M. Assessment of the significance of the historical experience of production cooperatives (artels) in modern economic practice. International Industrial portal 2010-08-23

13) Tabarintsev-Romanov, C. Cooperatives of Stalin's USSR

14) Aver'yanov, V. Russian artels. Unclaimed experience. Izborsky club. Institute of dynamic conservatism.

15) Lositsky, V. Children's technical creativity was the core of our industry, but now it is almost no. OTP [electronic resource] http://www.otr-online.ru/programmi/vladimir-lositskii-detskoe-39027.html

Paper sent to revision: 04.09.2015.

Paper ready for publication: 12.11.2015. 